\title{
Citizen-generated open data: An explorative analysis of 25 cases
}

\author{
Albert Meijer ${ }^{\mathrm{a}, *}$, Suzanne Potjer ${ }^{\mathrm{b}}$ \\ ${ }^{a}$ Utrecht University - School of Governance, Bijlhouwerstraat 6, Utrecht 3511 ZC, the Netherlands \\ ${ }^{\mathrm{b}}$ Utrecht University - Urban Futures Studio, Heidelberglaan 8, Room 043, Utrecht 3584 CS, the Netherlands
}

\section{A B S T R A C T}

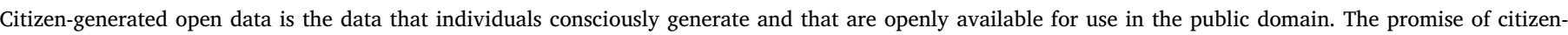

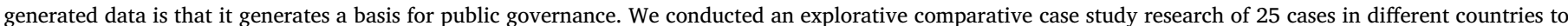

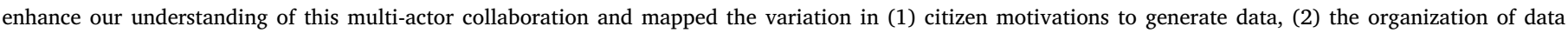

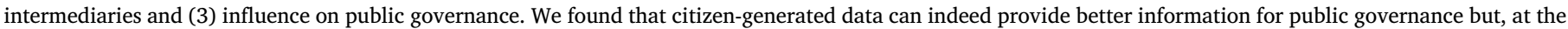

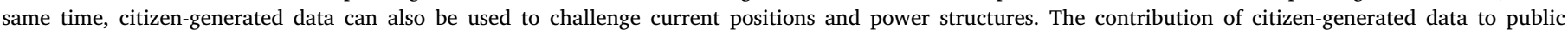
governance should thus be understood in terms of both collaboration and contestation.

\section{Introduction}

Open data are widely regarded as a means to strengthen democracies, enhance transparency and stimulate economic developments (Bertot, Jaeger, \& Grimes, 2010; Gasco-Hernandez, 2014; Zuiderwijk \& Janssen, 2014). Some authors acknowledge that open data is not only government data and research into other types such as open research data (Zuiderwijk-Van Eijk, Jeffery, Bailo, \& Yin, 2016) and public-private collaborations around open data is steadily growing (Susha, Janssen, \& Verhulst, 2017). Recently, Sieber and Johnson (2015) demonstrated that data generated by citizens is an important form of open data for public governance in the sense that it facilitates collaborative action by various actors to tackle public issues. This data can play a key role in bringing in new insights that can help to tackle problems as varied as air pollution, safety, school quality and mobility as is witnessed in the growing attention for citizen sensing (Gabrys, 2014). At the moment, however, a systematic theoretical and empirical understanding of open data generated by citizens and its relations to public problem solving is lacking.

Work on citizen-generated open data has been done by the thinktank Datashift but their findings are neither based on academic research nor are they positioned in the scientific literature (Datashift, No Data). Important work is being done on citizen science - defined as 'a form of research collaboration involving members of the public in scientific research projects to address real-world problems (Wiggins \& Crowston, 2011: 1) - but most conceptualizations focus on its scientific aspects rather than its value for tackling public issues (e.g. Bonney et al., 2009; Silvertown, 2009; for an exception: Wiggins \& Crowston, 2011). In addition, there are academic case studies on various forms of citizen- generated open data but these studies do not analyze the broader concept (e.g. Alexopoulos, Loukis, \& Charalabidis, 2014; Nam \& Pardo, 2014; King \& Brown, 2007; Burke et al., 2006; McCaffrey, 2005; Goodchild \& Glennon, 2010; Gabrys, 2014; Sheth, 2009; Tweddle, Robinson, Pocock, \& Roy, 2012; Gao, Barbier, Goolsby, \& Zeng, 2011). This paper fills part of this gap in the literature by developing an academic understanding of the citizen-generated open data based on an explorative case comparison.

The starting point forms a definition and the literature does not yet provide a generally accepted definition of citizen-generated open data. For our study, we define citizen-generated open data as the data that individuals consciously generate and that are openly available for use in the public domain. Citizen-generated data are a specific form of user-generated data (Krumm, Davies, \& Narayanaswami, 2008; Sieber \& Johnson, 2015). The latter refers to data from individual users that are either generated consciously - e.g. Facebook posts, Google searches, Airbnb ratings - or unconsciously - e.g. geodata from smart phones and cookies. Data from users are seen as highly valuable by companies, and through customer programs, cookies and consumer cards companies attempt to collect this data (Mayer-Schönberger \& Cukier, 2013). Only when user-generated data is used explicitly with a public purpose such as democratic debate or the development of solutions for public problems does it gain a 'civic' character and can it be called citizen-generated data. Citizen contribute data and open data intermediaries aggregate these to build datasets. This type of data is often openly available since its purpose is to influence public interactions. The term 'open' is used in a more generic sense as being available for use in the public domain and not in the strict definition that is used to describe requirements for open government data (for example: opengovdata.

\footnotetext{
* Corresponding author.

E-mail addresses: a.j.meijer@uu.nl (A. Meijer), S.P.Potjer@uu.nl (S. Potjer).
} 
org). This paper focuses on citizen-generated open data since this type of data is a relatively new development facilitated by internet technologies such as platforms and collaborative environments that challenges the traditional idea that data about public issues come from governments. Our paper aims to develop a theoretical and empirical understanding of this new type of data and its impact on interactions between actors in the public domain.

Citizen-generated open data raises a set of questions from an information science perspective related to the coverage, representivity, credibility and comparability of the data. This paper, however, emphasizes that we also need to understand how citizen-generated open data - as a form of multi-actor collaboration - helps to organize collective action around different problems or issues and thus the problem governance perspective can help us to study these new data collaborations and their impacts. From the perspective of public governance citizen-generated open data results from a multi-actor collaboration between citizens, intermediaries, governments and other actors in the public domain and it provides the basis for organizing multi-actor collaborations around different problems. The ambition of this explorative research is to map the variety of practices but to also enhance our understanding of the motivations of citizens and the impact of data on relations and interactions between governments, citizens and other actors in the public domain. The research question for this paper is: how do citizen-generated open data contribute to public governance? To answer this question we will developed a public governance perspective for understanding the relation between citizen-generated open data and governance and we explore citizen-generated open data empirically through a comparative and in-depth case analysis.

\section{Citizen-generated open data: a public governance perspective}

Open data are generally studied from a traditional perspective on the public domain: government organizations have data that they can or cannot make available to citizens (Bertot et al., 2010; Janssen, 2011; Zuiderwijk \& Janssen, 2014). Most analyses of open data therefore focus on the barriers for government to make data available and the extent to which these data are being used by citizens and other stakeholders. To understand citizen-generated open data, however, a broader perspective on the public domain is needed that conceptualizes governance as a multi-actor collaboration. This multi-actor perspective implies that data that are publicly available can be provided by government organizations but also by other actors such as companies, NGOs and citizens. In this perspective, open government data is only one specific form of open data next to other forms such as open business data, open scientific data and citizen-generated open data.

The public governance perspective has been described clearly by Stephen Osborne (2006, 2010). He argues that we should understand the evolvement of public governance over time as different paradigms (see also: Ansell \& Gash, 2008; Dunleavy, 2006; Torfing, 2012). Osborne (2006) distinguishes Old Public Administration (OPA), New Public Management (NPM) and New Public Governance (NPG). In the mode of OPA, the focus lies on the administration of rules and guidelines as established through political decision-making and implemented through bureaucracy. In the mode of NPM, performance of government is emphasized as achieved through market-inspired forms of public management. Lastly, in the mode of NPG attention turns towards collaboration, with various interdependent actors working together to achieve public value. In this last mode, data for supporting these collaborations can be provided by different actors that operate in the public domain.

The perspective of New Public Governance highlights that government is just one of the actors in the public domain and other actors also generate data for collective value production. Data from various actors is used in collaborative governance and in the literature these forms of usage are referred to as 'data collaboratives'. Susha, Janssen, \& Verhulst (2017: 151) refer to these as 'crosssector (and public-private) collaboration initiatives aimed at data collection, sharing, or processing for the purpose of addressing a societal challenge'. They highlight that the collaboratives raise a host of complex coordination problems but also generate much value for tackling a variety of issues in the public domain.

A specific actor in collaborative governance is the citizen and a specific source of data is citizen-generated data. The generation of data by citizens in emergency situations such as an earthquake can help to develop appropriate responses. Voluntary forms of citizen-generated data are crucial to this perspective since citizens are conceptualized as active participants in the public domain as highlighted by the rapidly expanding literature on coproduction in the public domain (for an overview: Brandsen \& Honingh, 2016). The typical role of a citizen is a participant in a civil society network who uses his/her own monitoring systems and digital collaboration environments to generate data. An important role for other actors such as companies and civil-society organizations is the organization of an initiatives - in the meaning of the Cambridge dictionary 'a new plan or process to achieve something or solve a problem' - through which citizen can generate and use open data.

The NPG perspective stresses that we should understand the initiatives of citizen-generated open data as complex collaborations between individual citizens that provide data, platform organizations that organize the data generation, collection and access to data and the broader network of public and private organizations that react to these initiatives and use the data for actions or interventions in the public domain. This means that crucial questions for understanding these complex collaborations are related to citizens, the data platform and the broader context of public and private organizations in the policy domain.

The first question related to this complex collaboration around citizen-generated open data is: under which conditions are citizens willing to provide data? This question aims to provide an understanding of the condition under which citizens are prepared to take the time and make the effort to contribute to common pool resources. This question about the willingness of citizens to participate can be positioned in the literature on coproduction (Alford, 2002; Bovaird, 2007; Brandsen \& Honingh, 2016). This literature on coproduction in general but also on specific forms of data coproduction such as 311 systems (Clark, Brudney, \& Jang, 2013) highlights that connecting to individual, collective or political motivations of citizens is crucial for engaging citizens in public tasks. On the basis of this literature, we propose that citizens will be willing to engage in citizen-generated open data initiatives if they feel it helps themselves, the group they feel they belong to or the public cause at large.

The second question focuses on the actor that manages the initiatives and thus aims to influence the policy domain: which actor organizes this data and how? This actor - the open data intermediary is a new type of actor for public governance. Open data intermediaries have received some attention in the literature on open data (Janssen \& Zuiderwijk, 2014; Magalhaes, Roseira, \& Strover, 2013) but then they refer to organizations that make open government data available to individual users. The open data intermediaries that we refer to in the other direction: they facilitate the generation of data by citizens. Little is known about who these actors are and why they intermediate this data generation. A specific issue for these intermediaries is the quality of data and the literature suggests that this quality can be improved through interventions such as user feedback (see e.g. Janssen \& Zuiderwijk, 2014). A general expectation could be that these data intermediaries will focus on the quality of the data to strengthen the idea that this is a neutral intervention in public governance.

The third question highlights the impact of the initiatives on the interactions between the various actors involved in public governance: how does the initiative influence public governance? Koppenjan and Klijn (2004) highlight that information is a key resource in network interactions and this the availability of data can have an impact on the 
relations between the various public governance actors. This means that actors will be interested in generating information about a neglected issue either as a basis for collective action or to shift the attention from the network in another direction. The cognitive framing of public governance can be influenced but this could also mean that public governance actors will choose to deliberately ignore certain information (Koppenjan \& Klijn, 2004).

In sum, from the perspective of New Public Governance, citizengenerated open data can contribute to public value realized through collaborative relationships between data intermediaries, citizens, government and other actors. The complex interactions between citizens, data intermediaries, governments and other actors that result in building collective data and that influence the impact of this data is still understudied. To enhance our understanding of citizen-generated open data and their potential impact, we analyzed various empirical cases of citizen-generated data to enhance our understanding of these platforms as complex interactions between individual citizens and organized actors.

\section{Research methods}

Our research aimed to generate an explorative empirical understanding of citizen-generated open data. To develop this understanding, we conducted an explorative comparative case analysis of 25 cases from around the world. The objective of this design was to provide an initial understanding of the variation of practices, the roles of different actors and the potential contribution of these practices to the public domain. An explorative comparative case study design is appropriate for the initial exploration of a concept and to understand the differences in practices, forms and relations (Eisenhardt, 1989; Yin, 1981).

Cases of citizen-generated open data were selected through various search strategies to identify a relevant and diverse sample. To start, we performed a Google search using multiple keywords such as 'citizen data', 'citizen science' and 'citizen-generated data'. In addition, we approached a range of key persons who might know about cases of citizen-generated open data. Finally, we applied a 'snowball' technique in which we used the cases we already found to find new cases of citizen-generated open data (Biernacki \& Waldorf, 1981). This search strategy does not pretend to be exhaustive in any sense but our ambition was to generate a set of cases that could provide insight in the variation in practices.

To find relevant cases but also map diversity, the cases were selected through a set of 'selective' and 'diversifying' criteria (Eisenhardt, 1989). The selective criteria consisted of five criteria that the cases had to meet:

- First, the cases had to be practices of citizen-generated open data, meaning that the data had to be provided by citizens on a voluntary basis and that the datasets were open for use by anyone.

- Second, the cases had to be in the implementation phase. We also identified various ideas for citizen-generated data but we only studied the practices that are actually being realized.

- Third, the cases had to use data generated by individuals, rather than organizations. The study focuses on citizen-generated data and not on data generated by (profit or non-profit) organizations.

- Fourth, the cases had to be concerned with public issues. Individuals can also generate data about for example the customer service of companies or specific hobbies. Our selection was limited to public issues and public organizations.

- Fifth and last, there had to be enough information available for analysis. We identified some interesting practices but we could not connect to the founders or obtain the information we needed through documents. These were left out from the sample.

In combination with these selective criteria, we used diversifying criteria to ensure sufficient diversity in the final selection. Specifically, we sought diversity in the initiatives with regards to the following dimensions: (1) the sector (environmental issues, education, mobility, public facilities, etc.), (2) actors running the platform (public, private and combinations), (3) type of data (qualitative and quantitative, geo and non-geo data), (4) roles of citizens (sensors, complainers, informers, evaluators), (5) size (from 250 to 35.000 contributing citizens) and (5) country (variation and also attention for non-western initiatives). On the basis of this combined selection strategy, we identified 25 cases from around the world (see Table 1).

We investigated this sample of 25 cases by making use of a variety of different data sources (Eisenhardt, 1989; Yin, 1981): an analysis of the initiative's website, complemented by an analysis of secondary sources and interviews. Extensive information was available on the websites of the initiatives and secondary material (media, previous studies) was available for many of the initiatives. We focused on the most informative media publications and key studies for the initiatives and we were restricted to the language that we can read (English, German, Dutch, Italian and Spanish). ${ }^{1}$

In addition, we held interviews with people from 12 cases in total through skype, telephone and e-mail. We approached all selected initiatives but we did not get a response from the other cases. The three questions for this research - motivations, organization and impact formed the basic structure for the interviews. The results were recorded in interview reports or were available directly as e-mail messages. These interviews provided more specific information about the platform owners and the usage by citizens.

We set up a file for each citizen-generated open data initiative that consisted of the data from the website, data from secondary studies, data from media publications and data from interviews. Systematic impact evaluations were not available for any of these citizen-generated open data initiatives and for this reason our study could only map the intentions and usage of the initiative and the intended impact.

The resulting research material was coded and analyzed to answer the three research questions: 1) Under which conditions are citizens willing to provide data? 2) Who organizes this data and how? 3) How does the initiative influence public governance? The numbers are small and therefore in depth discussions about the codes are preferable to a quantitative assessment of intercoder reliability. The data were coded and extensively discussed between the two researchers and the research assistant in this project to establish a shared understanding of how the 25 cases related to these questions (Firestone \& Dawson, 1982). Technology was a difficult variable to code since technology is a multifaceted concept. We chose to develop codes that provide an explorative understanding of some key differences and acknowledge that further conceptual work is needed to provide a theory-based understanding of the role of technology. The sector was sometimes easy to code - e.g. Bikemaps is about mobility - but in other cases more difficult due to the

\footnotetext{
${ }^{1}$ The following previous studies were used for the analysis of specific initiatives: ImproveTheNeighborhood (Kurniawan \& De Vries, 2015), Neighborhood NestWatch (Evans et al., 2005), ForestWatchers (Luz et al., 2014), Safecast (Brown et al., 2016), Smart Citizens (Grommé et al., 2017), USHADIDI (Marsden, 2013; Okolloh, 2009), Concerned Citizens of Abra for Good Government (Sohail \& Cavill, 2008), Missing Maps (Givoni, 2016), Bike Maps (Ferster et al., 2017; Nelson et al., 2015), Community Drones (Radjawali \& Pye, 2017), Mundraub (Larondelle \& Strohbach, 2016). In addition, we studied the following media sources: ImproveThe Neighborhood (Gelderlander, 2018), Neighborhood Nest Watch (The Denver Post, 2017), Open Elems Project (Computable, 2015), MafiaMaps (Bergamo Post, 2018), Safecast (Los Angeles Times, 2016), Smart Citizens (Open Democracy, 2017), Wheelmap (Merkur, 2017), USHAHIDI (New York Times, 2010), Missing Maps (Medical Facts, 2017), Bike Maps (Arizona State University Now, 2018), The Counted (The Guardian, 2016), Mundraub (Hannoversche Allgemeine, 2017), I Like Clean Air (ABC Online, 2017).
} 


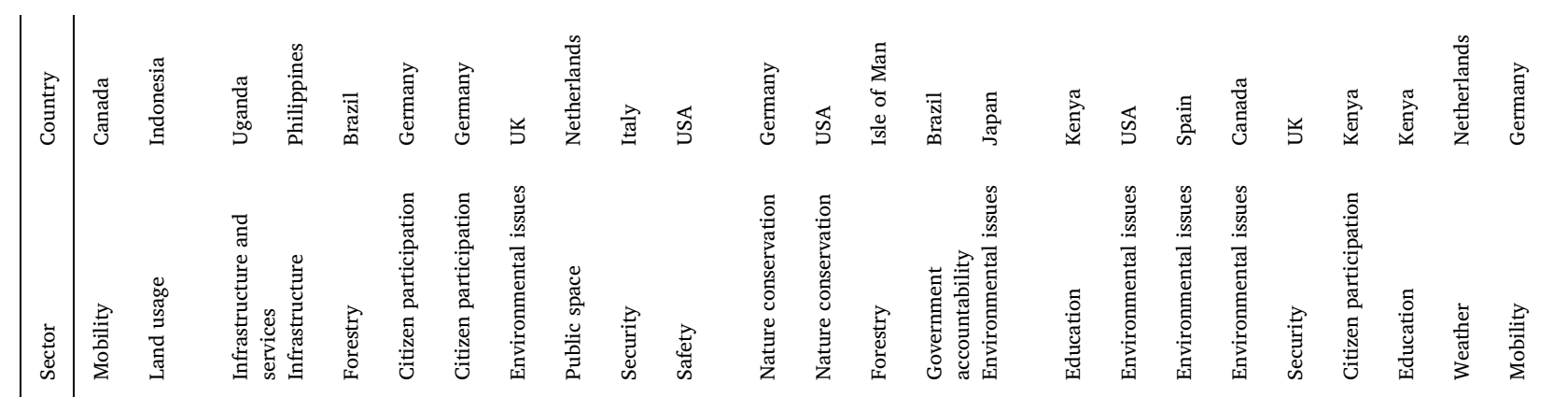

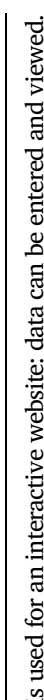

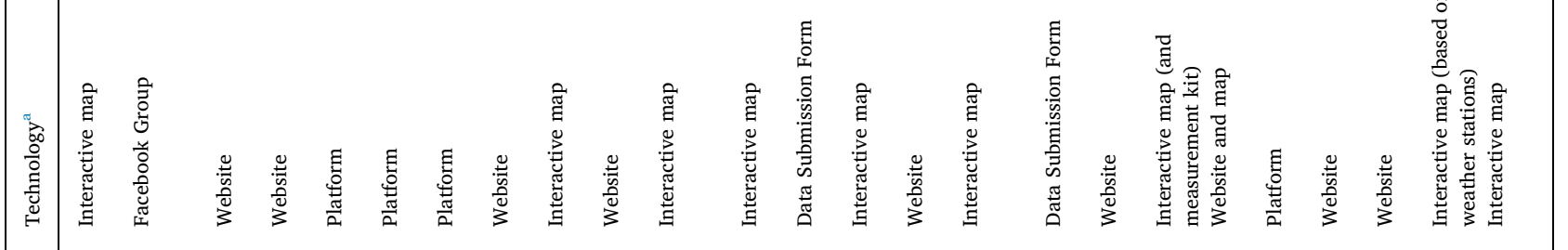

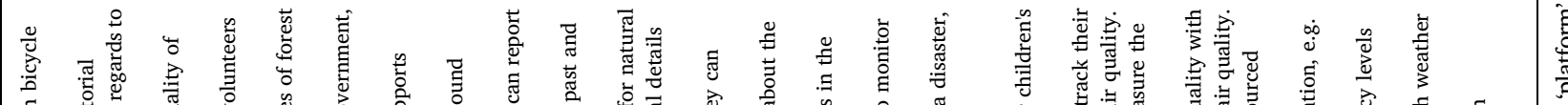

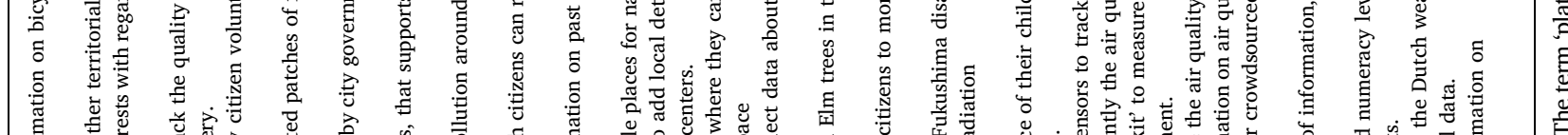

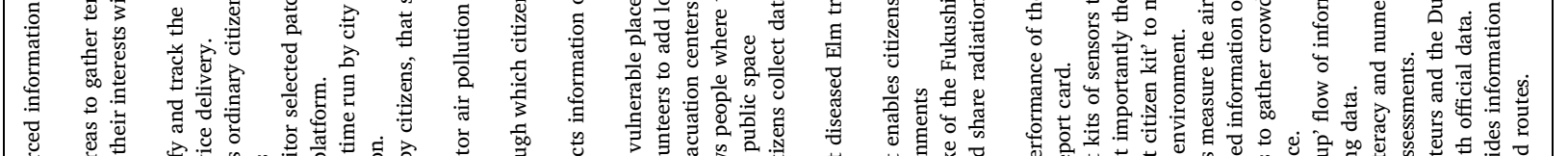

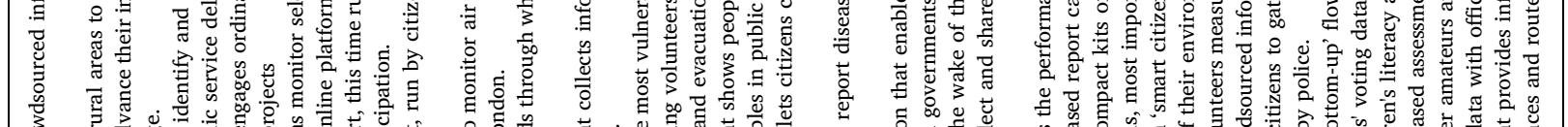

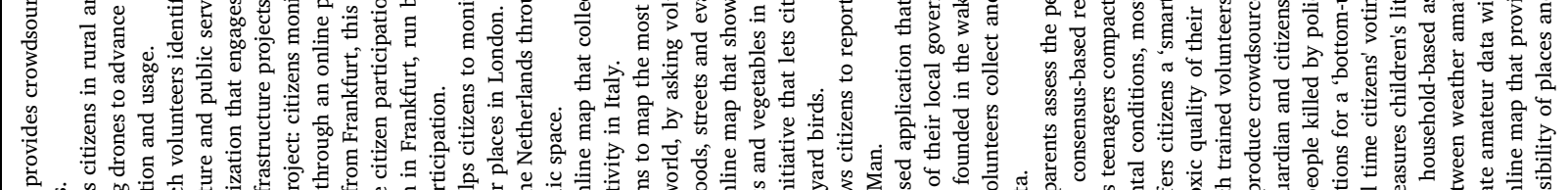

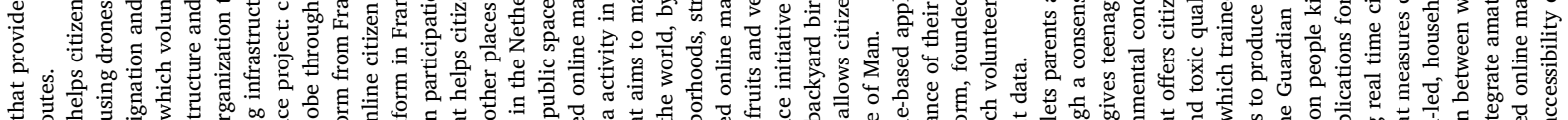

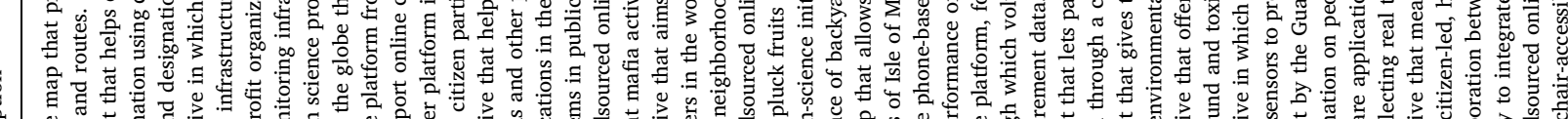

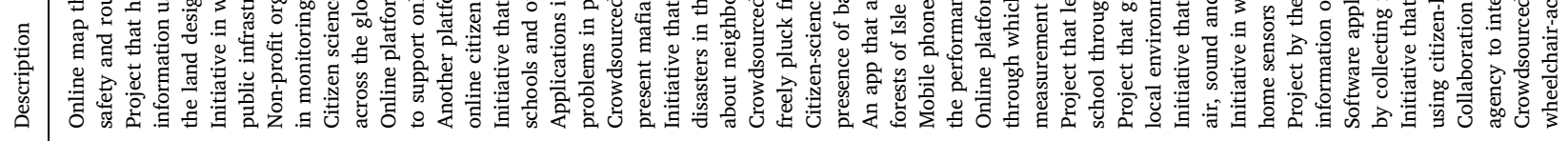

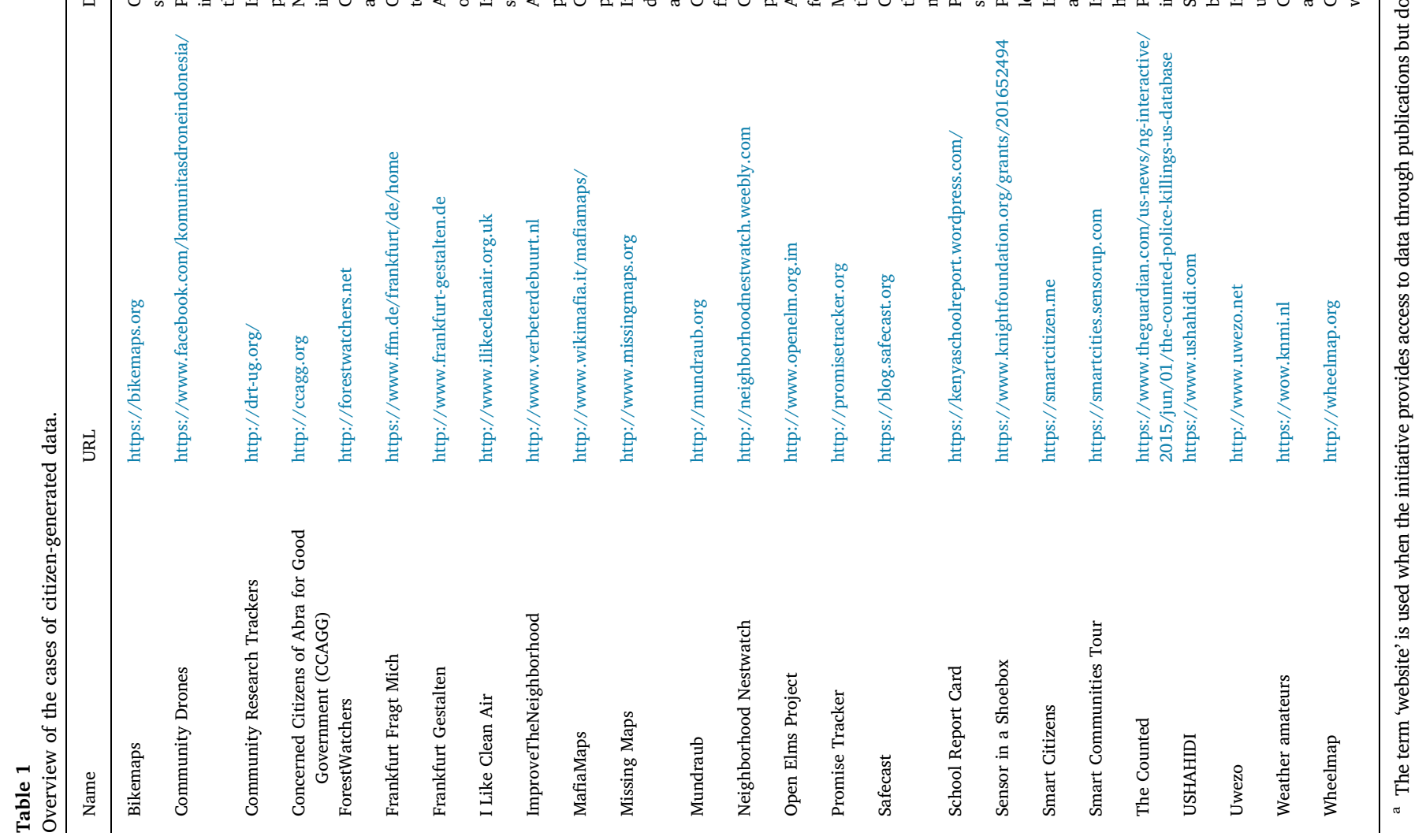


more generic focus of the initiative - e.g. Frankfurt Fragt Mich. We chose to provide sectoral codes and two codes referring to the generic type of government-citizen engagement: government accountability and citizen participation. The resulting dataset (see Table 1) was analyzed systematically on the basis of the three guiding empirical research questions to analyze the differences in practices, forms and relations.

\section{Comparative case analysis}

\subsection{Motivations of citizens}

The first empirical question in this explorative research was: under which conditions are citizens willing to provide data? We found that, according to the information provided by platform owners, citizens are willing to generate data when they find it in their individual (8 cases), collective (10 cases) or political interest (12 cases) to engage. These are in line with Alford's (2002) motivations for coproduction in the public sector that we mentioned in the theoretical section.

In the case of ImproveTheNeighborhood, for instance, citizens report street problems that bother them, such as trash or dog poo, thereby acting on an individual and collective interest (Gelderlander, 2018; Kurniawan \& de Vries, 2015). The crowdsourced online map of Mundraub can serve the individual interest of people to find the places where they can freely pluck fruits and vegetables (Hannoversche Allgemeine, 2017; Larondelle \& Strohbach, 2016). And Community Drones, an Indonesian project that helps citizens in rural areas to gather territorial information using drones, advances their interests with regards to the land designation and usage (Radjawali \& Pye, 2017). A driver can also be a group interest, as in the case of School Report Card, an initiative in which parents rate the performance of their children's school, providing input for the school to make improvements. The Project Sensor in a Shoebox gives teenagers compact kits of sensors to track their local environmental conditions, most importantly the air quality. Lastly, the interest can also be political, as in the case of Mafiamaps (Bergamo Post, 2018). One of the initiators of Mafiamaps: "We can make great efforts against Mafia organizations, but without geographically awareness the majority of people will still believe at the stereotype that Mafia is something far from them. Spreading the geographic knowledge is a way to make people more active against the Mafia phenomenon in their cities." (Respondent Mafiamaps) This quote illustrates that the data can help to help to mobilize people in the fight against mafia. Another example of political interests is Safecase in Japan. This is an online platform, founded in the wake of the Fukushima disaster, through which volunteers generate and share radiation measurement data. The data can help to put this safety issue higher on the agenda and demand political action for better safety protection. And a final example is The Counted, an initiative by The Guardian to gather crowdsourced information on people killed by police (The Guardian, 2016).

Next to these diverse interests, we found that an alternative motive for citizens to generate data: 'fun' (5 cases). The logic here seems to be people enjoy doing 'cool things' together on the internet. Examples can be given by the two citizen-science projects of ForestWatchers and Neighborhood Nestwatch, in which citizens contribute by respectively monitoring parts of the forest or counting the presence of backyard birds (Evans et al., 2005; Luz, Correa, González, Grey, \& Ramos, 2014; The Denver Post, 2017). Citizens participate in these projects because they find it important to contribute to science and/or because they enjoy the particular activity.

One case highlights a pattern that is possibly generic: keeping citizens engaged is not easy to realize. In this case of the Open Elms Project, citizens report sick Elm trees to the local Forest department (Computable, 2015). The Forest department actively tried to stimulate this, but - according to the initiator of the project - not enough: "What did the Forest Department all do on marketing? [It did a] press release, and also out in the country side there are signs, for walking paths. That was the start, but they did not continue, because they are not marketers.
They did not know how to do it. You need people that constantly engage, but this did not happen." (Respondent Open Elms Project).

Lastly, we found that it was also vital that applications for generating data were easy to use (all 25 cases). This type of motivation is what Herzberg, Mausner, and Snyderman (2011) calls 'hygiene factors': they denote the type of motives that impact satisfaction only when they are not sufficiently catered for. The example of Wheelmap, an application through which citizens can report on the wheelchair accessibility of local places, demonstrates this (Merkur, 2017). One of the people involved in Wheelmap notes: "That's why [the application of Wheelmaps] functions so well. You don't need to be an expert. (...) If you need to read two pages of instructions first, then people will not participate easily." (Respondent Wheelmap, Translated from Dutch).

This empirical analysis provided support for the expectation that individual, collective and political motivations played a role in engaging citizens in the citizen-generated open data initiative. In addition, the study of the cases resulted in the identification of 'fun' as a motivation for engagement and highlighted the importance of ease of use as a hygiene factor for engagement in citizen-generated open data. Finally, we found that keeping citizens engaged may be challenging when the newness of the initiative wears off.

\subsection{Roles of data intermediaries}

Our second empirical question in this explorative research was: who organizes citizen-generated open data and how? In our analysis we found that in many of the cases, third party organizations play a prominent role: 4 of the cases were organized by a public organization; in 14 cases, no public organization was involved and the initiative was instead taken up by a third party, such as a (social) enterprise, NGO or active citizens. Finally, in 7 cases the initiative was the product of a collaboration between a public organization and third party.

The public organizations that act as data intermediaries are often universities or research institutes but can also be governments. An example of a university is the initiative Sensors in a Shoebox from the University of Michigan. The initiative is about citizens harnessing themselves with smart city's sensors to gather their own data and using it to reshape the urban environment in a way that better meets their needs. This is an example of community action by a public organization. An example of a government that acts as data intermediary is Frankfurt Gestalten which is an online platform from Frankfurt run by city government to support online citizen participation. The platform aims to give citizen a channel for providing relevant information for public debate.

The NGOs that act as data intermediaries often have a specific objective. The environmental organization that set up I Like Clean Air, for example has the objective to push government to work on better air quality in the city and to raise awareness among citizens about the problem of air pollution (ABC Online, 2017). The Safecast initiative aims to call attention to the environmental radiation and other pollutants of the Fukushima Daichi Nuclear Power Plant disaster in 2011 (Brown, Franken, Bonner, Dolezal, \& Moross, 2016; Los Angeles Times, 2016). Another example is the Uwezo initiative. The data intermediary conducts annual large scale, citizen-led, household-based assessments that measure actual levels of children's literacy and numeracy across Kenya, Tanzania and Uganda. The Uwezo initiative is managed by Twaweza and this organization fosters what it calls an "ecosystem of change" through building on, as well as triggering, the actions of citizens to make a difference, and by scaling up such actions through brokering and supporting partnerships. Twaweza believes that lasting change requires bottom-up action.

Some data intermediaries are collaborations between a large set of public and private organizations. USHAHIDI, for example, is a collaboration of citizens and private companies like Omidyar network, Cisco, Ford foundation, Google, humanity united, MacArthur Foundation, Rockefelle foundation, Knight foundation and USaid 
(Marsden, 2013; New York Times, 2010; Okolloh, 2009). And ForestWatchers was created by a partnership between Brazil's National Institute for Space Research (INPE), the Federal University of São Paulo, the Citizen Cyberscience Centre (CCC) and the Open Society Foundations (Luz et al., 2014). The interesting thing is that these data intermediaries influence public governance of societal issues and they also result from networked collaborations between public and private organizations.

We thus found that citizen-generated open is often organized by a third party or through a collaboration between multiple public, private and/or civic actors. In line with the theoretical expectation, many data intermediaries focus on the quality of the data to strengthen the idea that this is a neutral intervention in public governance. These actors often have a specific ambition with generating the information but they are no interest group in the traditional sense since they highlight that they aim to generate data to inform public governance. This highlights that a new type of actor starts to play a role in public governance and the status of this actor is often not directly clear. Local governments are used to working with interest groups but these data platforms do not highlight specific interests but indicate that they aim to provide better data for public governance.

\subsection{Impact on public governance}

Our third empirical question in this explorative research was: how does the initiative influence public governance? We found that different actors have different perspectives on what constitutes a valuable outcome of citizen-generated open data. Our analysis highlighted that from a government perspective the initiatives mostly contribute to better policy implementation through collaboration with citizens and platform organizations (11 cases) or more government legitimacy by having other actors scrutinizing government policies (10 cases). From a citizen perspective, different types of influence can be identified. The dominant influence are raising the attention for an issue in the governance network (7 cases) or tackling an issue through collaborative action between citizens and other actors ( 2 cases).

Public organizations see data as valuable when it provides them with information for their own policy strategies or implementation as a basis for collaboration with different actors. An example of how citizengenerated open data helps public organizations with their implementation can be given by the case of Missing Maps, in which detailed information about remote areas is contributed by citizens, so that institutions and NGOs have better information for their response during natural disasters (Givoni, 2016; Medical Facts, 2017). Another valuable outcome for governments is that participation through citizen-generated open data may enhance their legitimacy as a government. This is for instance visible in the case of Promise Tracker, an application through which citizens of Brazilian cities provide local governments with local information - for instance on the quality of roads - and thereby monitor how well these governments follow-up on their promises. Another example is the Concerned Citizens of Abra for Good Government, a project that focuses on government accountability through citizen-generated open data (Sohail \& Cavill, 2008). Both practices contribute to government legitimacy when they show positive results but negative results may also undermine government legitimacy. As such, these initiatives can be viewed as a new addition to the system of checks and balances.

Citizens, on the other hand, find an outcome of citizen-generated open data valuable when it helps them to raise an issue with government and other actors in the policy domain. This for instance happens in the case of the Smart Citizen, where citizens measure the air and sound quality of their local environment, to be able to address the issue of pollution (Grommé, Ustek, Ruppert, \& Cakici, 2017; Open Democracy, 2017). In an experiment with the smart citizen kit in the city of Amsterdam, a majority of the participating citizens were "worried about the quality of their living environment and wanted to corroborate their suspicions with data." (Waag Society Amsterdam, 2014: 8; translated from Dutch) Or, citizens find contributing data valuable because it helps them to address a societal issue themselves. This for instance happens in the case of Mundraub, where citizens inform each other where to pluck fruits and vegetables in public space, thereby addressing issues of food waste and nature awareness themselves (Hannoversche Allgemeine, 2017). In some cases, citizens also generated data to achieve both at the same time. An example of this is the case of ImproveTheNeighborhood, where citizens can report problem in their local environment for government to fix, but can also suggest ideas for the community to take up (Gelderlander, 2018).

As values were perceived differently by different actors, a question is to what extent these values can both be realized in iniatives. This can sometimes be difficult, even for seemingly neutral topics. In the case of weather amateurs, the Dutch weather agency collaborated with weather amateurs in a research on city climates. The collaboration was valuable for both parties: for the weather agency, collaboration meant that they could significantly increase their amount of measurements. The weather amateurs, on the other hand, generate weather data for a hobby and liked to see their data used for professional research. The weather agency notes, however, that collaboration such as this is mostly suitable for explorative research: for more comprehensive forms of research, the data of weather amateurs is seen as not meeting the appropriate scientific standards. What this case thus shows is that a fruitful connection is possible, but at the same time also limited in its possibilities.

At a more general level, we observed that some cases aim to contest government policies whereas others focus on collaboration around shared policy objectives. In our material, we found that 12 cases aim to realize collaboration, 6 cases are about contesting policies and 7 cases are about both. Examples of collaboration are many of the nature monitoring initiatives (Neighborhood NestWatch, ForestWatchers, Open Elms Project, Weather amateurs). A clear example of contestation is The Counted which is about gathering crowdsourced information on people killed by police (The Guardian, 2016) but also the Promise Tracker which is a Mobile phone-based application that enables citizens to monitor the performance of their local governments. Examples of both are the environmental monitoring initiatives (Sensor in a Shoebox, I Like Clean Air) that create a basis for collaborative action but are also important to challenge the effectiveness of current government policies.

The cases highlight that governments react very differently to the presence of these new data actors. The initiatives about air quality (Smart Communities Tour, Smart Citizens, I Like Clean Air), for example, put this topic on the agenda but governments often do not directly know how to react to the identified problems. This is reinforced by the fact that the initiatives often have an innovative character and ask of government to work in new ways and use data from a different source than their own research. The initiator of the case of Bikemaps, in which citizens generate data about bicycle safety en route, talks about this problem when she explains why collaboration with government has proven difficult: "Municipalities are interested in using the data. Though, because municipalities haven't been using cycling safety data they seem a little uncertain as to how to integrate it into planning." (Respondent Bikemaps, see also: Nelson, Denouden, Jestico, Laberee, \& Winters, 2015; Ferster, Nelson, Winters, \& Laberee, 2017; Arizona State University Now, 2018). What a third party has to offer does not always match what public organizations want and/or need and therefore they often choose to ignore these initiatives.

Building an effective collaboration between the initiative and the government organization that needs to take action seems to be a key challenge for many of the initiatives. ImproveThe Neighborhood, for example, collects complaints about public space and shares this information with local governments so that they can take appropriate action. Some local governments appreciate this and process the complaints but others ignore them and only process complaints through their own channels. The success of the initiative largely depends on the 
willingness of the local governments to act upon the citizen-generated open data. In another case - the Open Elms Project - the initiator claimed it was easy to collaborate with government, because he organized the project 'pro bono' through a simple app and did not require funds. Or, as the initiator notes: "They were pretty open about this cooperation. If it had been internal, it would have never gotten off the ground. It's probably the way things should be done, it gave me freedom and it gave them freedom, it worked pretty well." (Respondent Open Elms Project) What we can thus conclude, that good collaboration is not a given, but instead requires that third parties and public organizations actively search for solutions that work for them both.

Finally, we found that collaborations do not only lead to certain outcomes, but also challenge and sometimes change the relationships of power between different actors. An example in which power relations were challenged but not changed are the two connected cases of Frankfurt Fragt Mich and Frankfurt Gestalten. Frankfurt Fragt Mich is the online participation platform of the municipality of Frankfurt that encourages citizens to suggest ideas for the city. This platform was raised even though active citizens had already raised a similar platform named Frankfurt Gestalten some time before. Even though the government-run platform was approached by the citizen-run platform, government decided not to collaborate with this group of active citizens, because: "[There's only a] small group of people that's active there, we want the whole citizenship." The result is that there are now two highly similar platforms in Frankfurt, one run by citizens and one run by government, of which the government-run Frankfurt Fragt Mich does not have significantly more reach.

The empirical analysis of expected impacts highlights that from a government perspective policy implementation and legitimacy are seen as the key impacts whereas citizens highlight attention for a topic and collective action as impacts. Collective action can have an overlap with policy implementation but it can also interfere with it. In terms of stakeholder collaboration, the analysis highlights that the data can form a basis for collaboration but also result in conflict (or just ignoring other actors). Collaboration depends on the topic and the willingness of different actors and, rather than collaboration, contestation is in some

Table 2

Overview of the findings from the explorative case analysis.

\begin{tabular}{|c|c|}
\hline Empirical question & Findings \\
\hline $\begin{array}{l}\text { 1. Under which conditions are } \\
\text { citizens willing to provide data? }\end{array}$ & $\begin{array}{l}\text { - Initiative connects to: } \\
\text { - Individual interests (8) } \\
\text { - Collective interests (10) } \\
\text { - Political interests (12) } \\
\text { - 'Fun' (5). } \\
\text { - Hygiene factor: ease of use (25) }\end{array}$ \\
\hline $\begin{array}{l}\text { 2. Who organizes this data and } \\
\text { how? }\end{array}$ & $\begin{array}{l}\text { - Public organization (government, } \\
\text { university) (4) } \\
\text { - Third party ((social) enterprise, NGO or } \\
\text { active citizens) (14) } \\
\text { - Collaboration between a public } \\
\text { organization and third party (7) }\end{array}$ \\
\hline $\begin{array}{l}\text { 3. How does the initiative influence } \\
\text { public governance? }\end{array}$ & $\begin{array}{l}\text { - Government perspective: } \\
\text { - Policy implementation through } \\
\text { collaboration (11) } \\
\text { - Third party facilitates government } \\
\text { accountability (10) } \\
\text { - Citizen perspective: } \\
\text { - Raising attention for an issue in the } \\
\text { network (7) } \\
\text { - Tackling an issue through } \\
\text { collaborative action (2) } \\
\text { - Interaction between actors: } \\
\text { - Collaboration (12) } \\
\text { - Contestation (6) } \\
\text { - Both (7) }\end{array}$ \\
\hline
\end{tabular}

The numbers in between brackets are the number of cases. The cases for the first and third questions add up to more than 25 since different types of value van be identified for several cases. cases the aim and this highlights that citizen-generated data initiatives should be understood from the frames of both collaboration and contestation.

\subsection{Conclusions of the comparative case analysis}

The comparative case analysis provided insight into the diversity of practices of citizen-generated open data for collaborative governance. The findings of this exploration are presented in Table 2 below.

The findings highlight the variety of practices, motivations, roles, impacts and challenges. Firstly, there were various differences in the motivations of citizens. We found different motivations for generating data: an individual interest, group interest or political interest, or because they 'like' the initiative. These findings highlight that initiatives can tap into a wide variety of citizen motivations to make the initiative work and engage citizens. A general consideration is that ease of use is of great importance as a 'hygiene factor'.

A second finding was that there are all kinds of collaborations between governments and third parties around initiatives of citizen-generated open data. We found the engagement of newspapers, companies, NGOs and individual citizen as data intermediaries. Sometimes they work by themselves, often with other organizations and often they desire to connect to governments. At the same time, these interactions are not always collaborative. The initiatives may not connect to government agendas and be ignored, or they may even contest or run counter to these government agendas.

In line with this observation, a third finding of the comparative case analysis was that citizens and government perceive the influence of citizen-generated open data differently. The dominant frame of government is coproduction, and from that frame, citizen-generated open data initiatives are seen as successful when they help to realize government objectives or strengthen citizen engagement. Citizens, on the other hand, start from their own personal engagement and focus on getting the attention of government and other actors for certain issues that they find important. They see an initiative as successful when it helps them to tackle a problem or put a subject on the governance agenda.

\section{Conclusions}

In this digitalized age, a myriad of ways has come to exist by which citizens can provide public organizations with valuable input. To give a name to this development, we have introduced the term citizen-generated open data: the data that individuals generate and that are openly available for use in the public domain. In this article, we have indicated that this type of open data can be understood from the perspective of public governance as a multi-actor process rather than from a perspective that puts government exclusively at the heart of interactions in the public domain (Alford, 2002; Koppenjan \& Klijn, 2004; Osborne, 2006; Torfing, 2012). As public governance emphasizes collaboration between different actors, the promise of citizen-generated open data is that, facilitated by data intermediaries, citizens generate data as a basis for collaborative governance of societal issues.

We conducted empirical research to explore this promise through an explorative comparative case study $(n=25)$. Our empirical research confirms this promise: citizen-generated open data can indeed provide an information basis for collaborative governance. Relevant information is generated about issues as diverse as the maintenance of public space, air quality and health of trees. This information facilitates collaborative actions aimed at producing public value and focuses attention on specific issues. At the same time, the explorative research also shows the more conflictuous side of things: citizen-generated open data also serve to contest the positions of powerful actors such as government. Citizens and platform actors can add value to the network of governance actors but also attempt to 'shake up the system' by bringing in information about specific issues and topics. 
The first contribution of this paper is that it provides a theoretical understanding of citizen-generated open data for collaborative governance as we positioned this type of data within the paradigm of public governance (Koppenjan \& Klijn, 2004; Osborne, 2006, 2010; Torfing, 2012). Collaboration in the production of data and collaboration on the basis of collective data are hallmarks of collaboration in governance networks. The promise of citizen-generated open data is that citizens generate data as a basis for collaborative governance trhough processes of coproduction (Alford, 2002; Bovaird, 2007; Brandsen \& Honingh, 2016). We conducted empirical research to explore this promise and found that this view on governance tends to neglect the contestation aspect. Citizen-generated open data also strengthen governance by offering new (data) checks and balances. On the basis of our empirical exploration we came to nuance the role of citizen-generated open data in new public governance: it is both about collaboration and contestation. The role of conflict in collaborative arrangement has been acknowledged (see for example Koppenjan \& Klijn, 2004) but many analyses tend to put the emphasis on multi-actor collaboration. Our empirical exploration highlights that we can only understand the role of citizens in new public governance if we acknowledge that both that public governance entails both collaboration and conflict.

The second contribution of this paper is the empirical understanding of the practices. The findings from the comparative analysis show firstly that citizens engage in the generation of data both to collaborate with government and to contest government positions and policies. We can make a distinction between friendly, adversary and neutral relations. Citizen-generated open data in friendly relations are used to coproduce public value. In adversary relations, citizen-generated open data are used to strengthen the position of citizens vis-à-vis government. In neutral relations, the data are used for citizen activities that do not directly affect the position of government. Secondly, the results highlight that citizen-generated open data is not only about government and citizens but also about intermediaries, companies and stakeholders. Platforms for citizen-generated open data are developed by different sorts of actors and the platform itself often forms an important actor in collaborative governance. Thirdly, the results highlight that an instrumental perspective on the impact of this data is too narrow. The instrumental impact is challenged since citizens and governments - and also platforms - have different perspectives on the value of citizengenerated open data that often highlight the political value of data.

The study is exploratory in nature and has a number of limitations. These limitations can form the basis for further research. Firstly, the study provides an overview of different types of initiatives but no information about the relevance, distribution and impact of these initiatives. More quantitative information about these initiatives is needed. Further research is needed to study more specifically how many of the different types of initiatives can be found and which ones prove to be effective. Secondly, we studied the interactions between government, citizens and platforms but we do not know to what extent the patterns we identified are representative for all cases. Additional work is needed to see whether similar patterns of interactions can be found in other cases and to see how the interactions are influenced by contextual conditions and subject matter.

This explorative research provides the basis for a research agenda. Qualitative research can enhance our understanding of how collaborative and contestative data platforms are being developed and when they prove to be influential in terms of attracting many citizens and making an impact on public governance. Quantitative research is needed to provide a systematic overview of the types of citizen-generated data platforms that exist and investigate the relation between their features and their impact. This type of research can build upon both the literatures on open data (e.g. Janssen, 2011; Zuiderwijk \& Janssen, 2014) and data collaboratives (Susha et al., 2017) but also on (new) public governance (Osborne, 2006; Stoker, 2006; Torfing, 2012) and coproduction (Alford, 2002; Bovaird, 2007; Brandsen \& Honingh,
2016). This combination of theoretical insights and qualitative and quantitative research will provide an understanding of the changing role of citizens in the production, collection, aggregation, analysis and use of data in the public sector.

In sum, our answer to the leading research question - how do citizen-generated open data contribute to public governance? - is not only an instrumental one - more effectiveness - but also an institutional one - more participation. The contribution of citizens does not only have a managerial meaning but also a democratic one (see also: Greenfield, 2013; Hollands, 2008). We found that citizen-generated open data can indeed help to 'map' and 'track' public spaces and thus provide better information for collaborative action. At the same time, citizen-generated open data can also be used to challenge current positions and power structures. In that sense, one could argue that citizengenerated open data also adds institutional quality of governance: the democratic process of checks and balances is strengthened now information resources are not only build up by governments but also by citizens.

\section{References}

Alexopoulos, C., Loukis, E., \& Charalabidis, Y. (2014). A platform for closing the open data feedback loop based on Web 2.0 functionality. eJournal of eDemocracy \& Open Government, 6(1), 62-68.

Alford, J. (2002). Why do public-sector clients coproduce? Toward a contingency theory. Administration \& Society, 34(1), 32-56.

Ansell, C., \& Gash, A. (2008). Collaborative governance in theory and practice. Journal of Public Administration Research and Theory, 18(4), 543-571.

Bertot, J. C., Jaeger, P. T., \& Grimes, J. M. (2010). Using ICTs to create a culture of transparency: E-government and social media as openness and anti-corruption tools for societies. Government Information Quarterly, 27, 264-271.

Biernacki, P., \& Waldorf, D. (1981). Snowball sampling: Problems and techniques of chain referral sampling. Sociological Methods \& Research, 10(2), 141-163.

Bonney, R., Cooper, C. B., Dickinson, J., Kelling, S., Phillips, T., Rosenberg, K. V., \& Shirk, J. (2009). Citizen science: A developing tool for expanding science knowledge and scientific literacy. Bioscience, 59(11), 977-984.

Bovaird, T. (2007). Beyond engagement and participation: User and community coproduction of public services. Public Administration Review, 67(5), 846-860.

Brandsen, T., \& Honingh, M. (2016). Distinguishing different types of coproduction: A conceptual analysis based on the classical definitions. Public Administration Review, 76(3), 427-435.

Brown, A., Franken, P., Bonner, S., Dolezal, N., \& Moross, J. (2016). Safecast: Successful citizen-science for radiation measurement and communication after Fukushima. Journal of Radiological Protection, 36(2), S82.

Burke, J. A., Estrin, D., Hansen, M., Parker, A., Ramanathan, N., Reddy, S., \& Srivastava, M. B. (2006). Participatory sensing. Center for Embedded Network Sensing. Retrieved from: http://escholarship.org/uc/item/19h777qd.

Clark, B. Y., Brudney, J. L., \& Jang, S. G. (2013). Coproduction of government services and the new information technology: Investigating the distributional biases. Public Administration Review, 73(5), 687-701.

Datashift (No Data). Using citizengenerated data to monitor the SDGs: A tool for the GPSDD data revolution roadmaps toolkit. Global Partnership for Sustainable Development Data. Available at: http://www.data4sdgs.org/resources/making-usecitizen-generated-data.

Dunleavy, P. (2006). Digital era governance: IT corporations, the state, and e-government. Oxford: Oxford University Press.

Eisenhardt, K. M. (1989). Building theories from case study research. Academy of Management Review, 14(4), 532-550.

Evans, C., Abrams, E., Reitsma, R., Roux, K., Salmonsen, L., \& Marra, P. P. (2005). The neighborhood nestwatch program: Participant outcomes of a citizen-science ecological research project. Conservation Biology, 19(3), 589-594.

Ferster, C. J., Nelson, T., Winters, M., \& Laberee, K. (2017). Geographic age and gender representation in volunteered cycling safety data: A case study of BikeMaps.org. Applied Geography, 88, 144-150.

Firestone, W. A., \& Dawson, J. A. (1982). Approaches to qualitative data analysis; intuitive, procedural, and intersubjective. Paper presented at the annual meeting of the American Educational Research Association, New York March 19-23.

Gabrys, J. (2014). Programming environments: Environmentality and citizen sensing in the smart city. Environment and Planning D: Society and Space, 32(1), 30-48.

Gao, H., Barbier, G., Goolsby, R., \& Zeng, D. (2011). Harnessing the crowdsourcing power of social media for disaster relief. IEEE Intelligent Systems, 26(3), 10-14.

Gasco-Hernandez, M. (Ed.). (2014). Open Government. Opportunities and challenges for public governance. New York: Springer.

Givoni, M. (2016). Between micro mappers and missing maps: Digital humanitarianism and the politics of material participation in disaster response. Environment and Planning D: Society and Space, 34(6), 1025-1043.

Goodchild, M. F., \& Glennon, J. A. (2010). Crowdsourcing geographic information for disaster response: A research frontier. International Journal of Digital Earth, 3(3), $231-241$. 
Greenfield, A. (2013). Against the Smart City. New York: Do Projects.

Grommé, F., Ustek, F., Ruppert, E., \& Cakici, B. (2017). Citizen data and official statistics: Background document to a collaborative workshop. ARITHMUS Working Paper Series, London.

Herzberg, F., Mausner, B., \& Snyderman, B. (2011). The motivation to work. New Brunswick: Transaction Publishers.

Hollands, R. (2008). Will the real smart city please stand up? Intelligent, Progressive or Entrepreneurial ? City, 12(3), 303-320.

Janssen, K. (2011). The influence of the PSI directive on open government data: An overview of recent developments. Government Information Quarterly, 28(4), 446-456.

Janssen, M., \& Zuiderwijk, A. (2014). Infomediary business models for connecting open data providers and users. Social Science Computer Review, 32(5), 694-711.

King, S. F., \& Brown, P. (2007). Fix my street or else: Using the Internet to voice local public service concerns. Proceeding ICEGOV '07 Proceedings of the 1st international conference on Theory and practice of electronic governance, Macao (pp. 72-80). Association for Computing Machinery (ACM) (pp. 72-80). . http://dl.acm.org/citation. $\mathrm{cfm}$ ?id $=1328076$

Koppenjan, J., \& Klijn, E. H. (2004). Managing uncertainties in networks: A network approach to problem solving and decision making. New York: Routledge.

Krumm, J., Davies, N., \& Narayanaswami, C. (2008). User-generated content. IEEE Pervasive Computing, 7(4), 10-11.

Kurniawan, M., \& de Vries, W. T. (2015). The contradictory effects in efficiency and citizens' participation when employing geo-ICT apps within local government. Local Government Studies, 41(1), 119-136.

Larondelle, N., \& Strohbach, M. W. (2016). A murmur in the trees to note: Urban legacy effects on fruit trees in Berlin, Germany. Urban Forestry \& Urban Greening, 17, 11-15.

Luz, E. F., Correa, F. R., González, D. L., Grey, F., \& Ramos, F. M. (2014). The forestwatchers: A citizen cyberscience project for deforestation monitoring in the tropics. Human Computation, 1(2), 137-145.

Magalhaes, G., Roseira, C. \& Strover, S. (October 2013). Open government data intermediaries: A terminology framework. Proceedings of the 7th international conference on theory and practice of electronic governance (pp. 330-333). ACM.

Marsden, J. (2013). Stigmergic self-organization and the improvisation of Ushahidi. Cognitive Systems Research, 21, 52-64.

Mayer-Schönberger, V., \& Cukier, K. (2013). Big data. A revolution that will transform how we live, work, and think. New York: Houghton Mifflin Harcourt.

McCaffrey, R. E. (2005). Using citizen science in urban bird studies. Urban Habitats, 3(1), $70-86$.

Nam, T., \& Pardo, T. A. (2014). The changing face of a city government: A case study of Philly311. Government Information Quarterly, 31, S1-S9.

Nelson, T. A., Denouden, T., Jestico, B., Laberee, K., \& Winters, M. (2015). BikeMaps. org: A global tool for collision and near miss mapping. Frontiers in Public Health, 3(53), 1-8.

Okolloh, O. (2009). Ushahidi, or 'testimony': Web 2.0 tools for crowdsourcing crisis in formation. Participatory Learning and Action, 59(1), 65-70.

Osborne, S. (2006). The new public governance? Public Management Review, 8(3), $377-387$.

Osborne, S. P. (Ed.). (2010). The new public governance: Emerging perspectives on the theory and practice of public governance. London: Routledge.

Radjawali, I., \& Pye, O. (2017). Drones for justice: Inclusive technology and river-related action research along the Kapuas. Geographica Helvetica, 72(1), 17-27.

Sheth, A. (2009). Citizen sensing, social signals, and enriching human experience. IEEE Internet Computing, 13(4), 87-92.

Sieber, R. E., \& Johnson, P. A. (2015). Civic open data at a crossroads: Dominant models and current challenges. Government Information Quarterly, 32(3), 308-315.

Silvertown, J. (2009). A new dawn for citizen science. Trends in Ecology \& Evolution, 24(9), 467-471.

Sohail, M., \& Cavill, S. (2008). Accountability to prevent corruption in construction projects. Journal of Construction Engineering and Management, 134(9), 729-738.

Stoker, G. (2006). Public value management: A new narrative for networked governance? American Review of Public Administration, 36(1), 41-57.

Susha, I., Janssen, M., \& Verhulst, S. (2017). Data collaboratives as "bazaars"? A review of coordination problems and mechanisms to match demand for data with supply. Transforming Government: People, Process and Policy, 11(1), 157-172.

Torfing, J. (2012). Interactive governance: Advancing the paradigm. Oxford: Oxford University Press.
Tweddle, J. C., Robinson, L. D., Pocock, M. J. O., \& Roy, H. E. (2012). Guide to citizen science: Developing, implementing and evaluating citizen science to study biodiversity and the environment in the UK. Wallingford: NERC/Centre for Ecology \& Hydrology.

Waag Society Amsterdam (2014). Eindrapportage smart citizen kit Amsterdam. Meten is weten? Last accessed February 2nd 2017, from http://waag.org/sites/waag/files/ public/media/publicaties/eindrapportage-sck-asd.pdf.

Wiggins, A., \& Crowston, K. (2011). From conservation to crowdsourcing: A typology of citizen science. Proceeding of the 44th Hawaii international conference system sciences (HICSS) (pp. 1-10). IEEE.

Yin, R. K. (1981). The case study crisis: Some answers. Administrative Science Quarterly, 26(1), 58-65.

Zuiderwijk, A., \& Janssen, M. (2014). Open data policies, their implementation and impact: A framework for comparison. Government Information Quarterly, 31(1), 17-29.

Zuiderwijk-Van Eijk, A., Jeffery, K., Bailo, D., \& Yin, Y. (2016). Using open research data for public policy making: Opportunities of virtual research environments. Proceedings of CeDEM16: International conference for e-democracy and open government.

\section{Media sources ${ }^{2}$}

ABC Online (2017). January 8 London air pollution kills about 10000 people annually. Available at http://www.abc.net.au/news/2017-01-09/london-activists-ramp-upfight-against-deadly-air-pollution/8168076.

Arizona State University Now (2018). January 30 Cycle of changes: New ASU bike initiatives help keep community safe. Available at https://asunow.asu.edu/20180129-solutionscycle-changes-new-asu-bike-initiatives-help-keep-community-safe.

Bergamo Post (2018). February 2 WikiMafia, quando la lotta si fa organizzando tutte le informazioni. Available at http://www.bergamopost.it/occhi-aperti/wikimafia-lalotta-si-organizzando-tutte-le-informazioni/.

Computable (2015). November 11 Gemeente moet big data meer benutten. Available at https://www.computable.nl/artikel/nieuws/business-analytics/5642837/250449/ gemeente-moet-big-data-meer-benutten.html.

Gelderlander (2018). February 5 Heumen verbetert de buurt het best. Available at https:// www.gelderlander.nl/nijmegen-e-o/heumen-verbetert-de-buurt-hetbest $\sim \mathrm{a} 7318 \mathrm{fcd} /$.

Hannoversche Allgemeine (2017). October 13 Hier können Sie in Hannover kostenlos Obst pflücken. Available at http://www.haz.de/Hannover/Aus-der-Stadt/Uebersicht/ Mundraub-Hier-koennen-Sie-in-Hannover-kostenlos-Obst-pfluecken.

Los Angeles Times (2016). July 27 Citizen science takes on Japan's nuclear establishment. Available at http://www.latimes.com/world/asia/la-fg-japan-safecast-snap-story. html.

Medical Facts (2017). January 31 Missing maps project—help het Rode Kruis. Available at https://www.medicalfacts.nl/2017/01/31/missing-maps-project-help-rode-kruis/.

Merkur (2017). November 13 Barrierefrei durch Zorneding dank Wheelmap. Available a https://www.merkur.de/lokales/ebersberg/zorneding-ort80605/barrierefrei-durchzorneding-dank-wheelmap-9356241.html.

New York Times (2010). March 13 Africa's gift to Silicon Valley: How to track a crisis Available at http://www.nytimes.com/2010/03/14/weekinreview/14giridharadas. html.

Open Democracy (2017). April 18 Citizenship and democratic production. Available at https://www.opendemocracy.net/democraciaabierta/mara-balestrini-valeria-righi/ citizenship-and-democratic-production.

The Denver Post (2017). April 28 Calling citizen scientists: Researchers want you to track nesting birds in your garden. Available at: https://www.denverpost.com/2017/04/28 / nestwatch-wants-citizens-tracking-birds/.

The Guardian (2016). August 12 If you value the Guardian's work to count police killings, please support our efforts. Available at: https://www.theguardian.com/membership/ 2016/aug/12/guardian-us-supporters-membership-the-counted.

Albert Meijer Professor Albert Meijer holds a chair in Public Innovation at the Utrecht University School of Governance. He is the chair of the permanent studygroup on egovernment of the European Group for Public Administration and member of the editorial board of Information Polity.

Suzanne Potjer Suzanne Potjer MSc is a PhD candidate at the Urban Futures Studio of Utrecht University. Her research is concerned with 'horizontal city networks'. 